\title{
Gilberto Gomes
}

\section{Negation of Conditionals in Natural Language and Thought}

\author{
Gilberto Gomes \\ Northern Rio de Janeiro State University, \\ CCH, PGCL 28013-602, Campos RJ, Brazil. \\ E-mail: ggomes@uenf.br
}

\begin{abstract}
External negation of conditionals occurs in sentences beginning with 'It is not true that if' or similar phrases, and it is not rare in natural language. A conditional may also be denied by another with the same antecedent and opposite consequent. Most often, when the denied conditional is implicative, the denying one is concessive, and vice versa. Here I argue that, in natural language pragmatics, 'If $A, \sim B$ ' entails ' $\sim($ if $A, B)$ ', but ' $\sim($ if $A, B)$ ' does not entail 'If $A, \sim B$ '. 'If $A, B$ ' and 'If $A, \sim B$ ' deny each other, but are contraries, not contradictories. Truth conditions that are relevant in human reasoning and discourse often depend not only on semantic but also on pragmatic factors. Examples are provided showing that sentences having the forms ' $\sim($ if $A, B)$ ' and 'If $A, \sim B$ ' may have different pragmatic truth conditions. The principle of Conditional Excluded Middle, therefore, does not apply to natural language use of conditionals. Three squares of opposition provide a representation the aforementioned relations.
\end{abstract}

Keywords: External negation, Implicative conditionals, Concessive conditionals, Pragmatic truth conditions, Boethius' theses, Conditional Excluded Middle, Contraries, Contradictories, Squares of opposition

For citation: Gomes G. "Negation of Conditionals in Natural Language and Thought", Logicheskie Issledovaniya / Logical Investigations, 2021, Vol. 27, No. 1, pp. 46-63. DOI: 10.21146/2074-1472-2021-27-1-46-63

\section{Introduction}

Negation in natural language involves complexities that are not at first sight evident. Horn [Horn, 2001, xiii] notes that, by contrast with 'the simplicity of the one-place connective of propositional logic (...), the form and function of negative statements in ordinary language are far from simple'. Quantification is one reason for the need to distinguish contrary from contradictory opposition. All $A$ is $B$ and No $A$ is $B$ are contraries, since they cannot be both true, but not contradictories, since they can be both false. The contradictory of $A l l A$ is $B$ is Some $A$ is not $B$, which is entailed by $N_{o} A$ is $B$, while the contradictory of 
the latter is Some $A$ is $B$, which is entailed by All $A$ is $B$. This set of relations is summarized in the well-known square of opposition. Another complication involves the Aristotelian distinction between term negation ( $A$ is not- $B$ ) and predicate denial ( $A$ is not $B$ ), and the distinction between these and the external negation of the Stoics (Not: $A$ is $B$ ), to which the modern Fregean negation can be traced [Horn, 2001, pp. 14-30].

Horn \& Wansing [Horn and Wansing, 2020] note that we do not usually find negation in natural languages in the place propositional logic would lead us to look, that is, in "sentence- or clause- peripheral position, as an external one-place connective (...)". However, external negation can and does occur in natural languages by means of the phrases it's not the case that, it isn't true that, it's false that or similar ones. Horn [Horn, 2001, pp. 364-365] views sentences using such phrases as cases of metalinguistic negation, and notes that they do not guarantee a presupposition-free reading of the negated sentence. However, this does not exclude that they are a form of external negation, nor does it preclude their use in our discussion of the negation of conditionals.

Thus, we can identify a form of external negation which consists in a complex sentence in which the main clause denies the truth of the proposition expressed in the subordinate clause. For example:

(1) It's not true that Phil was a good student.

Sentences of this type are usually employed to deny something that was said by someone else, or something that might be thought by someone else. In this sense, they are metalinguistic. Most frequently, negation of a sentence is displayed as internal negation:

(2) Phil wasn't a good student.

Although (1) and (2) would be used in different situations, to express different speaker intentions, as far as truth/falsity conditions are concerned, it can be accepted that they usually express propositions having the same truth/falsity conditions: if Phil was not a good student, the proposition they both usually express is true; if Phil was a good student, this proposition is false.

In the case of complex sentences with a subordinate clause, negation is usually obtained by adding the negative particle to the verb of the main clause. For example:

(3) A: When he lived with his father, Phil was a good student. B: No. When he lived with his father, Phil wasn't a good student. 
As far as truth/falsity conditions are concerned, (3)B is usually equivalent to:

(4) No. It isn't true that, when he lived with his father, Phil was a good student.

The subordinate clause in examples (3) and (4) is an adverbial clause (of time). The antecedent of a conditional sentence is also an adverbial clause. However, conditional clauses are a peculiar type of adverbial clause. The proposition expressed by the main clause of a sentence that has an adverbial clause of time, for example, is usually independently asserted by the utterance of the sentence. If we suppress the adverbial in (3) A, for example, we are left with Phil was a good student. We no longer know when A asserts this to have been the case, but we still have the information that Phil was a good student, at some time in the past, according to A. Not so with conditional sentences. Consider for example:

(5) If you study, you'll pass.

The person who utters this sentence is not thereby asserting that you will pass. If we suppress the adverbial in (5), we are left with the sentence You'll pass, and the proposition usually expressed by this sentence was not independently asserted by the utterance of the original sentence. This may be the reason why external and internal negations of a conditional may have different meanings:

(6) It's not true that if you study, you'll pass.

(7) If you study, you won't pass.

One way to explain this difference is to accept that external negation involves a denial of the conditional relation between the two clauses, which is not equivalent to a conditional denial of the proposition expressed by the main clause, as given by internal negation. What is being denied in (6) is a dependable relation between studying and passing. (7), by contrast, either suggests a paradoxical causal relation between studying and not passing, or is intended to express a concessive conditional (Even if you study, you still won't pass). With regard to truth/falsity conditions, if in reality you study and pass, (7) will have been shown to be false, but not (6). According to (6), you might have studied and not passed, but the possibility of studying and passing was not excluded.

Some philosophers have argued that the natural way to deny a conditional is to deny its consequent. According to this view, external negation of a con- 
ditional is exceptional, and when it occurs, it has the same meaning as the conditional presenting the negation of the original consequent. Thus, the negation of a conditional is in fact a conditional negation of its consequent. I argue in this paper that this is wrong. In section 6, I give a long list of attested examples of external negation in three languages, and in many of these there is a clear difference in meaning, including truth/falsity conditions, between the external negation of a conditional and the conditional with a negated consequent.

It is important to make clear that this is not a paper about the semantics of conditionals, but rather about their pragmatics, and its interest for logic. There is no consensus among the authors on how the distinction between semantics and pragmatics should be drawn. Here I will treat semantics as the study of the coded meaning of words and sentences, that is, of that part of their meaning that pertains to the language spoken by a certain population at a certain extended period of time and is relatively independent of the context of utterance and of the intentions of the speaker. By contrast, pragmatics here refers to the use of language by a speaker, or the understanding of language by a listener, in a certain context. It studies the meaning intended by the speaker and understood by the listener, which depends on the particular contexts in which words and sentences are used.

Many philosophers of language believe that the truth conditions of sentences are entirely provided by semantics. Contrary to this prevalent conception, I accept that pragmatics is sometimes necessary to establish the truth conditions of a sentence (for a defense of truth-conditional pragmatics, see [Recanati, 2010]). In particular, the point of view adopted in this article is that semantics must be supplemented by pragmatics in order to be able to explain how conditionals are used in human reasoning. Accordingly, in this paper I repeatedly refer to the meaning intended by the speaker when $\mathrm{s} /$ he uses a conditional, rather than to the meaning that a conditional sentence may have in itself.

In the following, 'negation of a conditional' is understood as the external negation described above applied to a conditional sentence. By contrast, a conditional 'with opposite consequent' is one presenting internal negation of an originally affirmative consequent, or an affirmative consequent instead of an originally negative one.

\section{A conditional entails the negation of a conditional with the same antecedent and opposite consequent}

A distinction between two types of conditionals will be essential in the following discussion. This is the distinction between concessive and implicative 
conditionals. $^{1}$ In a recent paper, I have argued that this distinction is best viewed as a pragmatic distinction, not as a semantic one Gomes, 2020]. There are semantic elements that contribute to a conditional receiving either a concessive or an implicative interpretation; for example, the presence of then for the latter, and of even if for the former. These semantic elements do not guarantee the respective interpretations, however, since there are pragmatically concessive conditionals without even if (some speakers may even admit in them the presence of then), and pragmatically implicative conditionals with even if Gomes, 2020.

From a pragmatic point of view, implicative conditionals are those in which the truth of the antecedent appears as a sufficient condition for the truth of the consequent, in a given context Gomes, 2009]. They are the conditionals that are most interesting from the point of view of logic, since they are the ones that are used in making inferences. By contrast, concessive conditionals, from the pragmatical point of view, are those in which the consequent is asserted as true (counterexamples in the literature are pragmatically implicative, though they have even if). In them, the antecedent usually expresses a condition that is somehow opposed to what the consequent expresses. While an implicative conditional conveys that the truth of its antecedent is a sufficient condition for the truth of the consequent, a concessive conditional conveys that the truth of its antecedent is an insufficient condition for the falsity of its consequent.

In so-called classic logic, the negation of a conditional entails the truth of its antecedent and the falsity of its consequent, a result that does not agree with the use of conditionals in natural language. This is a reason for those who think that the material conditional expresses the truth conditions of natural language conditionals to say that the negation of a conditional in natural language really means a conditional with opposite consequent. This is empirically false, however, or so I argue. Another interesting fact about classic logic is that it does not support Boethius' theses:

$$
(A \rightarrow B) \rightarrow \sim(A \rightarrow \sim B) \text { and }(A \rightarrow \sim B) \rightarrow \sim(A \rightarrow B)
$$

Intuitively, however, these entailments are very appealing and seem to be supported in inferential reasoning and in natural language use of conditionals. Let us begin our examination of the relation between the a conditional and the negation of a conditional with the same antecedent and opposite consequent by the case in which the former conditional is concessive and the latter implicative. For example:

\footnotetext{
${ }^{1}$ Implicative conditionals have been called standard or prototypical by Ducrot, 1972, genuine by J. Barker [Barker, 1973], strong by [Davis, 1983], robust by Lycan, 2001] and implicative by Declerck and Reed, 2001].
} 
(8) Even if she goes, I won't go.

(9) It's not the case that if she goes, then I'll go.

In human reasoning and discourse, it seems natural to agree that (8) entails (9). The fact that a concessive conditional entails the negation of an implicative conditional with opposite consequent was noted by Chisholm, 1946 , p. 301] and Goodman, 1947, p. 114]. Later developments in the theory of conditionals, however, tended to obscure the distinction between implicative and concessive conditionals, since it is difficult to attest by a purely semantic approach, and this observation by Chisholm and Goodman tended to be forgotten.

However, it is also to be noted that, conversely, implicative conditionals entail the negation of a concessive one with opposite consequent, as shown in the following examples.

(10) If he comes, then, as a consequence, I'll leave. Therefore: It is not the case that even if he comes, I won't leave.

(11) If butter is heated to $150^{\circ} \mathrm{F}$, then it melts. Therefore: It is not the case that even if butter is heated to $150^{\circ} \mathrm{F}$, it still doesn't melt.

(12) If she had been invited, then she'd be here. Therefore: It is not the case that even if she had been invited, she wouldn't be here.

This means that a concessive conditional may be denied by an implicative one with opposite consequent, and conversely, an implicative conditional may be denied by a concessive one with opposite consequent.

\section{The contradictory of a conditional}

The fact noted in the previous section raises the question of what the contradictory of a conditional is. A sure way to form the contradictory of a conditional, of course, is to use 'It is not the case that' before it:

(13) If it rains, the match will be cancelled.

(14) It is not the case that if it rains, the match will be cancelled.

According to Stalnaker's formal system, "the denial of a conditional is equivalent to a conditional with the same antecedent and opposite consequent (provided that the antecedent is not impossible)" [Stalnaker, 1968, pp. 48-49]. 
This equivalence involves the principle of conditional excluded middle, according to which either If $A, B$ or If $A, \sim B$ must be true. So (14) would be equivalent to:

(15) If it rains, the match will not be cancelled.

According to this equivalence, (13) and (15) are contradictories. This example seems to confirm the proposed equivalence. It might be objected, however, that someone who asserts (14) may not have (15) in mind, but rather the following:

(16) If it rains, the match may be cancelled (if it rains heavily), but it may also not be cancelled (if it rains lightly).

In this case, (13) and (15) would be neither true nor false, because the expression it rains, in both of them, is not sufficiently precise for the case being considered. [Stalnaker, 1981] argues that conditional excluded middle is a principle of the abstract semantics of conditionals that may fail to apply to natural language sentences due to semantic indeterminacy. Some sentences should thus be considered as neither true nor false. However, there are examples for which Stalnaker's equivalence fails and do not seem to involve any indeterminacy.

(17) A:If Bill goes to the party, Mary will go.

B:No. If Bill goes to the party, Mary won't go.

From a pragmatical point of view, B may have three different reasons for asserting the conditional present in his answer: (i) it may be intended as a concessive conditional, equivalent to: Even if Bill goes to the party, Mary still won't go; (ii) it may be asserted because B thinks that if Bill goes to the party, it is because Mary will not go (since he will only go if she does not); and (iii) it may be intended as equivalent to: If Bill goes to the party, then as a consequence Mary won't go (e.g. because she does not want to meet him). ${ }^{2}$

Now, suppose that in fact Mary will go to the party if she finishes her work in time, regardless of Bill's going or not, and that Bill will go to the party if he gets better from his cold, regardless of Mary's going or not. In these circumstances, A's conditional is false since it is possible that Bill goes to the party and Mary does not. Consequently, its external negation is true:

(18) It is not the case that if Bill goes to the party, Mary will go.

\footnotetext{
${ }^{2}$ This means that (17) B will have different speaker meanings according to these three possibilities. The same sentence, with arguably the same semantic meaning, would be used in three different contexts with different speaker meanings. This difference is not relevant, however, to the argument made here, and is mentioned only to be sure that all possibilities of interpretation have been covered.
} 
However, in the same circumstances, B's conditional is also false, whether it is asserted for any of the three reasons mentioned above, because Bill and Mary may very well both go to the party.

Now, is there any indeterminacy in either conditional that might justify their being considered as neither true nor false? In its natural interpretation, A's conditional establishes a relation between Bill's going to the party and Mary's going to the party. B's conditional may be interpreted as establishing the lack of such a relation (if interpreted as a concessive conditional) or as establishing a relation between Bill's going to the party and Mary's not going to the party. Saying that someone will go or not to a party does not involve any vagueness (at least not any that is relevant to the evaluation of the conditional). It will definitely prove true or false when the party occurs. As to the relation in question, different theories of conditionals will explain it differently. However, it is difficult to see what indeterminacy might be present in it that would justify these conditionals being considered as neither true nor false.

Of course, assuming Stalnaker's theory, one can always say that A's and B's conditionals in (17) do not establish in a determinate way the world in which Bill goes to the party that is most similar to ours, and are therefore neither true nor false. However, the argument is question-begging. It presupposes the theory that we want to put to test. Moreover, it contradicts the intuition that each of these sentences must be either true or false.

In order to make this point clearer, let's compare (13)-(15) with (17)-(18). There is a relevant vagueness in If it rains which accounts for the indeterminacy of (13) and (15) in truth value. If we precisify this antecedent in a way suitable for the context considered, e.g. with heavily or lightly, the indeterminacy vanishes. According to what was supposed in (16), if it rains heavily, the match will be cancelled, while if it rains lightly, it will not.

Regarding (17) (If Bill goes to the party, Mary will/won't go), by contrast, there is no available precisification of its antecedent that would render either conditional true in the context considered. If in reality Mary will go to the party if she finishes her work in time, regardless of Bill's going or not, there is no relevant vagueness in the conditional clause If Bill goes to the party.

We conclude that, pragmatically, the contradictory of a conditional is not a conditional with same antecedent and opposite consequent. This means that with regard to their use in reasoning and discourse, two conditionals with the same antecedent and opposite consequents are contraries, because they cannot be both true, but may be both false. A more complex form using It's not the case that or It's not true that is necessary for making the contradictory of a conditional. 


\section{A concessive conditional denies an implicative conditional with the same antecedent and opposite consequent and vice versa}

Going back to the rain/match example, it is certain that (15) (If it rains, the match will not be cancelled) can also be used to deny (13) (If it rains, the match will be cancelled), because - in accordance with Boethius' thesis - it entails (14) (It is not the case that if it rains, the match will be cancelled). It was probably on the basis of such uses that Stalnaker proposed the previously mentioned equivalence, failing to acknowledge the difference between contrary and contradictory denials involved here.

However, it must be noted that, in their most natural pragmatic interpretation, (13) suggests a context in which it is used as an implicative conditional, while (15), in the same context, would be used as a concessive conditional, meaning the same as:

(19) Even if it rains, the match will not be cancelled.

However, both could have a different pragmatic meaning, in a different context. Suppose that the president of the club has asked the players to paint the exterior walls of the club and the best time to do this is the time the match is scheduled to be played. So the match will probably be cancelled. Then one of the players, who is eager to play, utters (15) (If it rains, the match will not be cancelled). Since painting the exterior walls would not be possible under the rain, he reasons, the match will not be cancelled if it rains. In this context, (15) is not pragmatically concessive, but implicative. This is shown by the fact that it would accept a paraphrase with then, as a consequence:

(20) If it rains [oh, how nice!], then, as a consequence, the match will not be cancelled [since we won't be able to paint the exterior walls of the club].

What conditional could be used to negate this sentence, in this context? Suppose a second player replies to the one who uttered (13) or (20):

(21) No, you're wrong. If it rains, the match will be cancelled. [Because the interior walls of the club also need painting, and the rain will not prevent painting them.]

We see that here it is (13) (If it rains, the match will be cancelled) that is used to deny (15) (If it rains, the match will not be cancelled), and not vice versa. The painting vs. playing context, however, imposes an interpretation to (13) which is different from the usual one. Here, the conditional does not accept a paraphrase with then, as a consequence. By contrast, it means the same as: 
(22) Even if it rains, the match will still be cancelled.

We conclude that, when a conditional is used to deny another with the same antecedent and opposite consequent, if the latter is implicative, the former will usually be concessive. Moreover, when it is a concessive conditional that is denied by another with the same antecedent and opposite consequent, the latter will usually be implicative, as shown in the following example:

(23) A: If it rains, the match won't be cancelled.

B: No. If it rains, the match will be cancelled.

In their most probable interpretation, (23)A is pragmatically a concessive conditional (equivalent to a paraphrase with Even if) and (23)B is in this case an implicative conditional (equivalent to a paraphrase with then as a consequence).

There are also cases, however, in which an implicative conditional If $A, B$ may be denied by a conditional If $A, \sim B$ that is also interpreted as implicative, but one needs additional reason for the latter interpretation. For example:

(24) A: If Bob comes, Linda will come-because she loves him.

B: No, if Bob comes, then Linda WON'T come-because he has rejected her.

Here, speaker B does not mean that Bob's coming will be an insufficient reason for Linda to come and [therefore] she will not come, as B would if $\mathrm{s} /$ he had used a concessive conditional. B is suggesting instead that Bob's coming, if it occurs, will be a sufficient reason for Linda NOT to come, that is, to refrain from coming (for the reason mentioned, that he has rejected her), even if she might have a different reason to do so. Although usual, it is not necessary, therefore, that the two conditionals with the same antecedent and opposite consequents that deny each other are one implicative and other concessive, from a pragmatic point of view. They may, in special cases, be both implicative, or both concessive.

\section{The negation of a conditional does not entail a conditional with the same antecedent and opposite consequent}

Some logical systems also accept the converses of Boethius' theses:

$$
\sim(A \rightarrow B) \rightarrow(A \rightarrow \sim B) \text { and } \sim(A \rightarrow \sim B) \rightarrow(A \rightarrow B)
$$

These are valid in classical logic, in Stalnaker's conditional logic (as discussed above), in Wansing's $\mathbf{C}$ system and the first of them is valid in intuitionist logic [Wansing, 2005]. However, I argue here that the use of conditionals in natural discourse and reasoning does not support the converses of Boethius's 
theses. Statements with the phrase It's not true that preceding an implicative conditional do not entail the same conditional with an opposite consequent.

It must be noted, however, that Wansing's connexive logic $\mathbf{C}$ uses a strong type of negation that does not express untruth, but rather definite falsity. It is the De Morgan negation from the four-valued first-degree entailment logic (FDE), in a language with implication. Four truth values are admitted: true, false, neither true nor false, and both true and false. Therefore, the falsity conditions in the semantics of $\mathbf{C}$ are not conditions of when a formula is not true, but conditions that specify when a formula is definitely false. Thus, negation in $\mathbf{C}$ is neither suitable nor has it been intended to formalize an external natural language negation expressed by It's not true that or It's not the case that. It must also be noted that, although it validates the converses of Boethius's theses, $\mathbf{C}$ does not validate conditional excluded middle. ${ }^{3}$

It must be recognized that there are many cases in which If $A$, not $B$ seems equivalent to the external negation of If $A, B$. The following are two attested examples of such cases:

(25) It's not true that if your employer isn't paying you, you're therefore unemployed. (Paraphrasable as: If your employer isn't paying you, you're not therefore unemployed.)

(26) If God does not exist, then it's not the case that if I pray, my prayers will be answered. (Paraphrasable as: If God does not exist, then if I pray, my prayers will not be answered.)

It should also be noted, however, that the conditional with the same antecedent and opposite consequent that seems to be entailed by the negation of an implicative conditional is usually interpreted as a concessive conditional. In (25) and (26), for example, the paraphrases given are in turn paraphrasable as:

(27) Even if your employer isn't paying you, you're not therefore unemployed.)

(28) If God does not exist, then even if I pray, my prayers will not be answered.)

However, (6), (9), (18) are examples in which the negation of an conditional cannot be paraphrased by a conditional with opposite consequent. Here are other examples:

(29) It is not the case that if Beth and Nick both have blood type AB, their child will not have blood type A.

(30) If Beth and Nick both have blood type AB, their child will have blood type A.

\footnotetext{
${ }^{3}$ I am grateful to Heinrich Wansing for these observations.
} 
(31) Even if Beth and Nick both have blood type AB, their child will have blood type A.

Example (29) does not entail either (30) or (31), because (29) is true (since it is possible for the child of such a couple to have blood type A), but (30) and (31) are certainly false (since it is also possible for such a child to have blood types $\mathrm{B}$ or $\mathrm{AB})$.

(32) It's false that if you use an underarm deodorant you'll get breast cancer.

Agreeing with this sentence certainly does not entail believing that underarm deodorant use is an effective means to avoid the development of breast cancer:

(33) If you use an underarm deodorant you won't get breast cancer.

Nor does it entail believing the corresponding concessive conditional to be true:

(34) Even if you use an underarm deodorant, you won't get breast cancer.

The latter conveys that you will not get breast cancer, while (32) is a more cautious statement that does not implicate this conclusion.

\section{Negation of a conditional in natural language}

Although David Lewis (unlike Stalnaker) recognizes that conditionals with opposite consequents may be both false (see section 7), he also failed to properly evaluate the use of negation of conditionals in natural language, as shown in the following quotation, where he discusses a settlement of the problem of ties regarding the similarity of worlds (one in which both $A \square \rightarrow F$ and $A \square \rightarrow \sim F$ are considered false):

This reasonable settlement, however, does not sound so good in words. $A \square \rightarrow F$ and $A \square \rightarrow \sim F$ are both false, so we want to assert their negations. But negate their English readings in any straightforward and natural way, and we do not get $\sim(A \square \rightarrow F)$ and $\sim(A \square \rightarrow \sim F)$ as desired. Rather negation moves in and attaches only to the consequent, and we get sentences that seem to mean $A \square \rightarrow \sim F$ and $A \square \rightarrow \sim \sim F(\ldots)$ ([Lewis, 1973, p. 61])

It is true that in many contexts If $A, \sim B$ seems a more straightforward and natural way of denying If $A, B$. This is not to say, however, that the more elaborate form $\sim($ if $A, B)$ is not available and widely used in natural language (English or other). A search in the Internet provides one with lots of examples. Here is a sample of attested examples in three languages: 
It is not true that if some is good then more is better.

Hence it is not true that if $K$ is such a composant of $M$ every point of $M$ is a limit point of $\mathrm{K}$.

It is not true that if you dream about someone they are thinking of you. It's not true that if I owned all of those things, that would make me happy.

It is not true that if a person talks about suicide, they will not kill themselves. It is not true that if you touch a baby bird the parents will reject it.

It's not true that if you go to "any tiny village in China", they have an internet café.

It's not true that, if I'm rich, I'm happy.

It's not true that if a technology has benefits, it will automatically get accepted by the public.

It's not true that if you're unhappy, so are your children.

It isn't true that if we can't think of something right away then we don't know it. It isn't true that if you liked the Don Williams album, then you'll buy the Vern Gosdin album.

I definitely know it isn't true that if you are having periods your estrogen is "fine".

It isn't true that if someone looking at you thinks you're beautiful, then you are.

However, it's not the case that if your camera does not have one or other of these modes then it cannot do that sort of photography.

It's not the case that if one candidate wins all three then he or she should be the nominee.

It's not the case that if we just feel bad enough about ourselves we will be motivated to change.

It's not the case that if you make it through the first 10 years, your marriage is divorce-proof.

It's not the case that if you're eligible you'll get the money.

It is not the case that if we don't immediately solve the Futenma issue we can't deepen relations.

It is not the case that if one has faith then one's reason is canceled out.

It is not the case that if the US isn't powerful enough, then China, Russia, or some caliphate will be.

It's not true that wisdom teeth crowd your teeth if they grow in impacted. It's not true that wasps don't sting you if you keep still.

In addition, it's not true that all intruders will flee if confronted.

It's not true that you will suffer if you come out with your ideas in public. It's not true that you gain weight if you're on birth control.

It's false that if others change, we will also change.

It's false that if your gutters are falling off, you must replace them.

It's false that if we keep running large deficits then we get increases to our debt-to-GDP ratio $(\ldots)$.

Ce n'est pas vrai que si dans l'année un homme marié n'a pas régularisé il ne fera jamais. 
Ce n'est pas vrai que si le sexe va bien, tout va bien entre 2 personnes.

Ce n'est pas vrai que si les ordinateurs fonctionnent c'est grâce à notre mâ̂trise de la physique quantique!

Ce n'est pas vrai que si le citoyen qui se fait arrêter n'est pas armé le policier ne devrait pas se servir de son arme.

Ce n'est pas vrai que si un enfant n'a pas suivit [sic] un programme éducatif avant l'école il aura des difficultés d'apprentissage.

C'est faux que si l'on fait un vœu, il se réalise.

[C]'est faux que si on ne paye pas la pension[,] il y a abandon.

$(. .$.$) il est faux que si un sujet croit que a est \mathrm{F}$, alors il existe quelque chose a, à propos duquel le sujet croit qu'il est $\mathrm{F}$.

No es verdad que, si se promueve el desarrollo económico, después se obtendrá la dictadura.

No es verdad que si un triángulo tiene tres ángulos entonces un cuadrado tiene cuatro ángulos.

No es verdad que si usas aceite sintético una vez tienes que seguir poniéndole para siempre.

No es verdad que si no eres gaditano no te respeten en el carnaval.

Por otro lado no es verdad que si dedicaran más dinero a mejorar sus productos no tendrían que anunciarlos.

No es verdad que "si estudias aprobas" [sic].

No es verdad que si el niño balbucea o emite sonidos, no tiene problemas en el oído.

[E]s falso que si cocemos una seta con una cuchara de plata y ésta ennegrece, se trata de una seta tóxica, y si no, es comestible.

Es falso que si te arrancas una cana, saldrán más (...).

Es falso que si uno fuma marihuana[,] termina consumiendo cocaína

It is thus clear that there are many, many cases in which negation does not and sometimes indeed cannot-move in and attach only to the consequent, as Lewis states.

Consider one more example:

(35) It's not true that if Jones loves his children, then he's not a criminal.

It is quite obvious that the truth of (35) does not entail (36):

(36) If Jones loves his children, then he's a criminal.

And interpreting (36) as a concessive conditional would not help to make it viable as a paraphrase for (35), as shown by the following unambiguously concessive version of it:

(37) Even if Jones loves his children, he's a criminal.

Someone who asserts (37) is convinced that Jones is a criminal, while someone who asserts (35) is just admitting that this is possible, even if he loves his children. 


\section{Conditional excluded middle}

Our conclusion entails that the principle of conditional excluded middle is not valid for natural language conditionals. According to this principle, either $A \rightarrow B$ or $A \rightarrow \sim B$ must be true. However, examples such as (5)-(7), (17)-(18), (29)-(30), (32)-(33) and (35)-(36) show that it is possible in natural language to consider two conditionals with same antecedent and opposite consequent as both false.

Lewis rejected the principle of conditional excluded middle, but for a different reason. He noted that there may be ties in comparative similarity among possible worlds, so that a world in which Bizet and Verdi are both French may be as similar to ours as one in which they are both Italian [Lewis, 1973 p. 61]. Thus, he does not believe that either If Bizet and Verdi were compatriots, they would be French or If Bizet and Verdi were compatriots, they would not be French must be true. As regards the external negation of conditionals in natural language, he seems rather (as shown in the previous section) to subscribe to the mistaken notion of an equivalence between the linguistic forms corresponding to $\sim($ if $A, B)$ and If $A, \sim B$, respectively Lewis, 1973, p. 61].

A problem for the rejection of conditional excluded middle seems to be the distributivity of the conditional operator over disjunction (see Bennett, 2003, p. 185]):

$$
A \rightarrow(B \vee C) \therefore(A \rightarrow B) \vee(A \rightarrow C)
$$

Replacing $C$ by $\sim B$, we get:

$$
A \rightarrow(B \vee \sim B) \therefore(A \rightarrow B) \vee(A \rightarrow \sim B)
$$

Since $A \rightarrow(B \vee \sim B)$ is a logical truth, the principle of conditional excluded middle seems to be proved. However, distributivity of the conditional operator over disjunction is valid in classic propositional logic, in which this operator is the material conditional operator, but need not be valid for other varieties of the conditional connective.

Concerning the implicative use of natural language conditionals in reasoning and discourse, distributivity over disjunction is certainly not valid, as shown by the following example:

(38) If Anna has blood type A, then her genotype is either AA or AO.

This is true, but does not entail that either (39) or (40) is true, since they are both pragmatically false:

(39) If Anna has blood type A, then her genotype is AA.

(40) If Anna has blood type A, then her genotype is AO. 
The proposition conveyed by the uttering of (39) would be pragmatically true if any person having blood type A (and not just Anna, if she does have it) had genotype AA (which is not the case), and similarly for (40) in relation to genotype AO. We conclude that distributivity over disjunction is not a reason for accepting conditional excluded middle for natural language conditionals, and that conditional excluded middle must in fact be rejected, as shown by the counterexamples given above.

\section{Conditional squares of opposition}

The relations among negations of conditionals and conditionals with opposite consequents may thus be summarized in three squares of opposition, as follows (contradictories indicated by the diagonals).
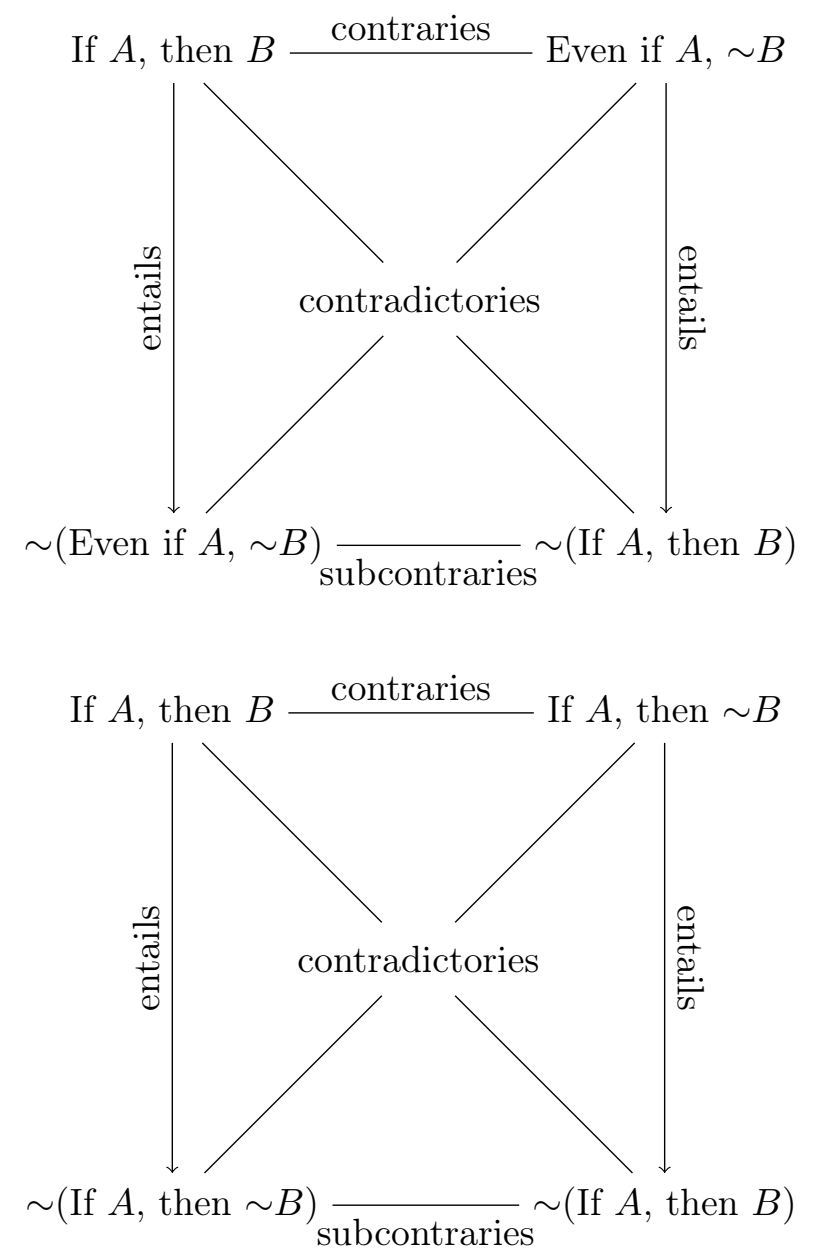


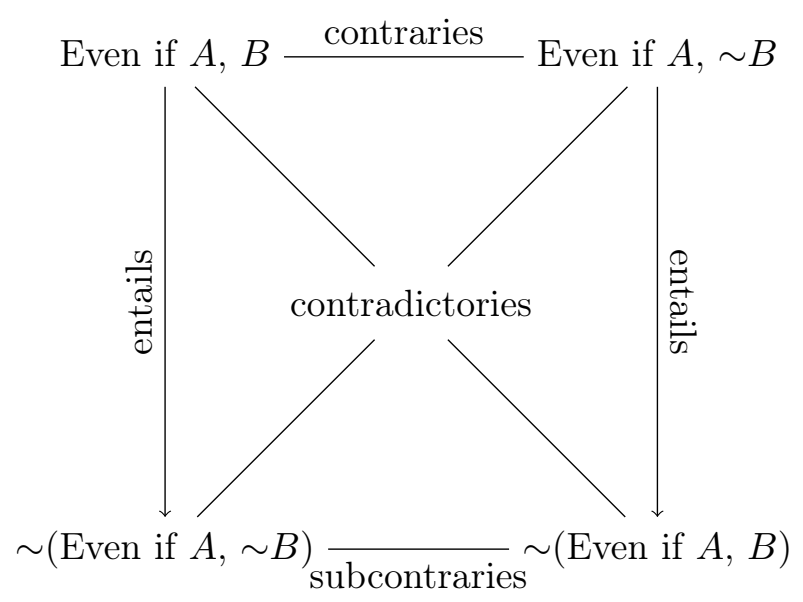

\section{Conclusions}

(i) Not (if $A$, then $B$ ) cannot always be paraphrased as If $A$, then not $B$, so the former does not entail the latter in natural language.

(ii) Similarly, Not (if $A$, then $B$ ) does not entail Even if $A$, not $B$.

(iii) Moreover, Not (even if $A, B$ ) does not entail If $A$, then not $B$.

(iv) Similarly, Not (even if $A, B$ ) does not entail Even if $A$, not $B$.

(v) On the other hand, If $A$, then $B$ entails Not (even if $A$, not $B$ ).

(vi) Similarly, Even if $A, B$ entails Not (if $A$, then not $B$ ).

(vii) Moreover, If $A$, then $B$ also entails $N o t$ (if $A$, then not $B$ ).

(viii) And similarly, Even if $A, B$ also entails Not (even if $A$, not $B$ ).

(ix) Therefore, If $A$, then $B$ and Even if $A$, not $B$ are contraries, not contradictories. Similarly, the pair If $A$, then $B$ and If $A$ then not $B$ and the pair Even if $A, B$ and Even if $A$, not $B$ are also pairs of contraries, not of contradictories.

(x) Therefore, the principle of conditional excluded middle does not apply to the use of conditionals in natural language.

\section{References}

Barker, 1973 - Barker, J.A. "Hypotheticals: Conditionals and theticals", Philosophical Quarterly, 1973, Vol. 23, No. 93, pp. 335-345. 
Bennett, 2003 - Bennett, J. A Philosophical Guide to Conditionals. Oxford: Oxford University Press, 2003.

Chisholm, 1946 - Chisholm, R. "The contrary-to-fact conditional", Mind, 1946, Vol. 55, pp. 289-307.

Davis, 1983 - Davis, W. "Weak and strong conditionals", Pacific Philosophical Quarterly, 1983, Vol. 64, pp. 57-71.

Declerck and Reed, 2001 - Declerck, R. and Reed, S. "Some truths and nontruths about even if', Linguistics, 2001, Vol. 39, No. 2, pp. 203-255.

Ducrot, 1972 - Ducrot, O. Dire et ne pas dire. Paris: Hermann, 1972.

Gomes, 2009 - Gomes, G. "Are necessary and sufficient conditions converse relations?", Australasian Journal of Philosophy, 2009, Vol. 87, No. 3, pp. 375-387.

Gomes, 2020 - Gomes, G. "Concessive conditionals without even if and nonconcessive conditionals with even if', Acta Analytica, 2020, Vol. 35, No. 1, pp. 1-21.

Goodman, 1947 - Goodman, N. "The problem of counterfactual conditionals", Journal of Philosophy, 1947, Vol. XLIV, No. 5, pp. 113-128.

Horn, 2001 - Horn, L.R. A Natural History of Negation. Stanford (CA): CSLI Publications, 2001.

Horn and Wansing, 2020 - Horn, L.R. and Wansing, H. "Negation", The Stanford Encyclopedia of Philosophy, https://plato.stanford.edu/archives/spr2020/ entries/negation/, Spring 2020 edition.

Lewis, 1973 - Lewis, D. "Counterfactuals and comparative possibility", Journal of Philosophical Logic, 1973, Vol. 2, reprinted in Ifs, ed. by W.L. Harper, R. Stalnaker, and G. Pearce. Dordrecht: Reidel, 1981, pp. 57-85.

Lycan, 2001 - Lycan, W.G. Real conditionals. Oxford: Oxford University Press, 2001.

Recanati, 2010 - Recanati, F. Truth-Conditional Pragmatics. Oxford: Oxford University Press, 2010.

Stalnaker, 1968 - Stalnaker, R.C. "A theory of conditionals", in: Studies in Logical Theory, ed. by N. Rescher, Oxford: Blackwell, APQ Monograph No 2., reprinted in Ifs, ed. by W.L. Harper, R. Stalnaker, and G. Pearce, Dordrecht: Reidel, 1981, pp. $41-55$.

Stalnaker, 1981 - Stalnaker, R.C. "A defense of conditional excluded middle", in: Ifs, ed. by W.L. Harper, R. Stalnaker, G. Pearce. Dordrecht: Reidel, 1981, pp. 87-104.

Wansing, 2005 - Wansing, H. "Connexive Modal Logic", in: Advances in Modal Logic. Volume 5, ed. by R. Schmidt et al. London: King's College Publications, 2005, pp. 367-383. 